\title{
Interactive Influence of Enzyme Loading and Initial Concentration of Fermentable Sugars on Simultaneous Saccharification and Fermentation of Cellulose to Ethanol
}

\author{
Jalil Shadbahr, Faisal Khan, and Yan Zhang
}

\begin{abstract}
Enzyme loading and initial concentrations of fermentable sugars are the key parameters in the simultaneous saccharification and fermentation (SSF) process to produce bioethanol. To study the interactive influence of enzyme loading and initial concentration of sugars on the final ethanol yield and concentration, batch SSF experiments were carried out at three enzyme loadings (10, 15 and 20 FPU/g cellulose) and two levels of initial concentrations of fermentable sugars (glucose and mannose). Results indicated that the maximum ethanol yield and concentration were obtained at high level of sugar concentration with intermediate enzyme loading ( 15 FPU/g cellulose). Increasing the enzyme loading from intermediate level (15 FPU/g cellulose) to high level (20 FPU/g cellulose) diminished the ethanol yield due to the inhibitory effect of the glucose and insufficient amount of yeast. Experimental results of SSF process also reveal that an efficient mixing between the phases helps to improve the ethanol yield significantly.
\end{abstract}

Index Terms-Bioethanol, enzyme loading, ethanol yield, simultaneous saccharification and fermentation.

\section{INTRODUCTION}

Bioethanol produced from lignocellulosic biomass have been considered as one of the most attractive and promising renewable energy sources [1]. The most abundant sources of lignocellulosic materials are forestry and agricultural residues which are considered as renewable, low-priced, noncompetitive to food sources, and available sources for future energy [2]. The chemical composition of the lignocellulosic materials mainly consists of cellulose, hemicellulose, and lignin. Compositions of the lignocellulosic materials are different in cellulose, hemicellulose, and lignin contents as well as in the structure of the materials and how they entangled together. In the complicated created matrix of the lignocellulosic material, cellulose is well protected and surrounded by hemicellulose and lignin which makes the cellulose recalcitrant for degradation and producing glucose out of it. In order to make the cellulose more accessible for enzymes, pretreatment of the lignocellulosic substrate is unavoidable to have an efficient enzymatic cellulose hydrolysis in next step [3]-[6].

Manuscript received April 8, 2016; revised August 8, 2016.

J. Shadbahr, F. Khan, and Y. Zhang are with the Department of Process Engineering at Memorial University of Newfoundland, St John's NL A1B 3X5 Canada (e-mail: jshadbahr@mun.ca, fikhan@mun.ca, yanz@mun.ca).
Numerous research studies have demonstrated that SSF process is capable of improving the biomass conversion by reducing the inhibitory impact of converted sugars [7]-[10]. Usually, a high ethanol concentration and yield from SSF is prerequisite to make the process economically feasible. Nevertheless, the contribution of enzyme costs to the economics of lignocellulosic biofuel production continues to be a major barrier for the commercial-scale production of bioethanol [11]-[13]. There is potential for cost reduction by optimizing the operating conditions of SSF process so that maximum ethanol concentration and yield can be achieved at relative lower enzyme loading.

Main factors affecting the final ethanol concentration and yield of SSF process include substrate concentration, enzyme loading, solution $\mathrm{pH}$, and reaction temperature [14], [15]. Due to the compromise between reaction conditions for hydrolysis and fermentation processes, the optimal $\mathrm{pH}$ (5.0) and reaction temperature $\left(37^{\circ} \mathrm{C}\right)$ of SSF process turned out to be very restricted [14], [16]. Dissimilarly, the optimal substrate concentration and enzyme loading are very difficult to be determined [17]-[19]. To obtain high ethanol concentration and yield, a high substrate concentration and, hence high water insoluble solids (WIS), has to be used in the SSF process [20]-[22]. However, high substrate concentration leads to substrate inhibition, which substantially lowers the rate of the hydrolysis and metabolism of yeast [21]. For optimal enzyme loading, increasing the dosage of enzymes, to a certain extent, is able to enhance the yield and rate of the hydrolysis, but also significantly increases the cost of the process [23]. Systematic optimization of the SSF process regarding the substrate concentration and enzyme loading needs to be carried out.

Monomeric sugars released from the pretreatment process are also served as the feedstock of SSF process. The initial concentration of the fermentable sugars varies based on the pretreatment method and the raw biomass materials used. The concentration of fermentable sugars definitely affects the final ethanol concentration and yield of a SSF process because sugar concentrations have significant impacts on the reaction rates of both enzymatic hydrolysis and fermentation. It is therefore important to investigate how the initial concentrations of fermentable sugars influence the SSF process. So far very limited research work has been performed to address this issue [24]. In the current study, the interactive influence of the initial concentrations of fermentable sugars and enzyme loading on the SSF of cellulose to ethanol has been explored to provide the profound insight on the process improvement. 


\section{MATERIALS AND METHODS}

\section{A. Feedstock}

Extra pure microcrystalline cellulose, ACS grade glucose and $99 \%$ mannose were used as feedstock for SSF process. Cellulose content was adjusted to $5 \%(\mathrm{w} / \mathrm{v})$ and initial fermentable sugar concentration was considered at high and low levels in order to evaluate the impact of sugars concentration on ethanol yield.

\section{B. Enzymes}

To provide the activities of 10,15 , and $20 \mathrm{FPU} / \mathrm{g}$ cellulose, cellulose enzyme from Trichoderma reesei (ATCC 2921), was utilized and supplemented with $\beta$-Glucosidase with the fixed activity of $30 \mathrm{U} / \mathrm{g}$ cellulose.

\section{Yeast Preparation}

Preparation of the yeast for fermentation process consists of four steps: (1) Propagation of saccharomyces cerevisiae cells purchased from VWR onto the agar plate under the sterile condition and storage in fridge at $4{ }^{\circ} \mathrm{C}$; (2) Preparation of YPD solution from YPD broth (HIMEDIA) with the concentrations of yeast extract, peptone, and dextrose being 10, 20, and $20 \mathrm{~g} / \mathrm{L}$ respectively; (3) Addition of the cells to autoclaved YPD solution and shaking in a rotary shaker at $30^{\circ} \mathrm{C}$ for 24 hours; (4) Separation of the grown cells by centrifuge, washing the cells with DI water twice and storage in fridge for further use.

\section{SSF Experiments}

An experimental setup consists of $250 \mathrm{~mL}$ jacketed stirred tank reactor and a Julabo FP 50 heated/refrigerated circulator for temperature control. Experiments were carried out at $37^{\circ} \mathrm{C}$ and $\mathrm{pH}$ of 5.0 for 96 hours. During SSF experiments, solution $\mathrm{pH}$ was monitored with Accumet $\mathrm{AB} 15$ plus $\mathrm{pH}$ meter and adjusted by $1 \mathrm{M} \mathrm{NaOH}$ solution. Agitation was provided by a baffled magnetic stirrer at the speed of $350 \mathrm{rpm}$. Three chemical components were also added as nutrients supplementary to reactor with the following concentrations: $\left(\mathrm{NH}_{4}\right)_{2} \mathrm{HPO}_{4}: 0.5 \mathrm{~g} / \mathrm{L}, \mathrm{MgSO}_{4} \cdot 7 \mathrm{H}_{2} \mathrm{O}: 0.025 \mathrm{~g} / \mathrm{L}$, and Yeast Extract: $1 \mathrm{~g} / \mathrm{L}$.

The SSF process takes place in a single reactor with a series of the simultaneous reactions presented in equation 1 . Produced glucose from the hydrolysis process is then fermented to ethanol by yeast.

$$
\text { Cellulose } \rightarrow \text { Cellobiose } \rightarrow \text { Glucose } \rightarrow \text { Ethanol }
$$

In order to evaluate the SSF performance, ethanol yield was considered as the determinant parameter. Total amount of sugars in the reaction media includes glucose, mannose, and convertible glucose from cellulose and defined as:

$$
\text { Total sugars }=[G]_{0}+[M]_{0}+1.111[C]_{0}
$$

where the $[G]_{0},[M]_{0}$, and $[C]_{0}$ are the initial amount of the glucose, mannose, and cellulose, respectively. The constant 1.111 is the stoichiometry conversion factor of cellulose to glucose. According to total available sugars, the theoretical maximum ethanol that can be calculated as:

$$
\text { Max Ethanol = 0.511[Total sugars] }
$$

The constant 0.511 is the stoichiometry conversion factor of glucose to ethanol. The ethanol yield is defined as the ratio of experimentally produced ethanol to maximum theoretical ethanol by Eq. 4.

$$
\text { Ethanol yield }(\%)=\frac{[E]_{f}-[E]_{0}}{0.511\left([G]_{0}+[M]_{0}+1.111[C]_{0}\right.}
$$

\section{E. Analysis Method}

The Dionex HPLC system including a binary HPG-3200SD pump, an ACC-3000 autosampler, RefractoMax 521 RI detector, and Chromeleon 7 software were used for the analysis of concentrations of ethanol, glucose, mannose, and cellobiose. All the samples were taken in duplicate, centrifuged, filtered by $0.2 \mu \mathrm{m}$ sterile filter and finally stored in a freezer for further analysis. Two Agilent columns: Agilent Hi-Plex H and Agilent Hi-Plex Pb columns were implemented to analyze the samples. Temperature for the RI detector was adjusted at $55^{\circ} \mathrm{C}$ and for the HPLC column was set to $50^{\circ} \mathrm{C}$. DI water and $0.005 \mathrm{M}$ sulfuric acid both with the flowrate of $0.7 \mathrm{~mL} / \mathrm{min}$, were used as the mobile phases for Agilent Hi-Plex Pb and Agilent Hi-Plex H columns respectively.

\section{RESULTS AND DISCUSSION}

In order to investigate the impacts of initial sugars concentration and enzyme loading on the ethanol yield and productivity in SSF process, six experiments were performed at different conditions of investigated parameters. Table I shows the detailed conditions of the six experiments.

TABLE I: INITIAL SUGAR CONCENTRATIONS, ENZYME AND YEAST LOADINGS FOR SSF EXPERIMENT

\begin{tabular}{cccccc}
\hline \hline Exp. & $\begin{array}{c}\text { Glucose } \\
\text { Concentration } \\
(\mathrm{g} / \mathrm{L})\end{array}$ & $\begin{array}{c}\text { Mannose } \\
\text { Concentration } \\
(\mathrm{g} / \mathrm{L})\end{array}$ & $\begin{array}{c}\text { Cellulase } \\
(\text { FPU/g } \\
\text { cellulose })\end{array}$ & $\begin{array}{c}\beta \text {-Glucosidase } \\
(\mathrm{U} / \mathrm{g} \text { cellulose })\end{array}$ & $\begin{array}{c}\text { Yeast } \\
\mathrm{g} \text { dry } \\
\text { cell/L }\end{array}$ \\
\hline 1 & 5 & 4.5 & 10 & & \\
2 & 10 & 9 & & & \\
3 & 5 & 4.5 & 15 & 30 & 5 \\
4 & 10 & 9 & & & \\
5 & 5 & 4.5 & 20 & & \\
6 & 10 & 9 & & & \\
\hline
\end{tabular}

Note: The amount of cellulose substrate was fixed at 5\% (w/v) for all the experiments

It must be noted that the other parameters of the reaction such as $\mathrm{pH}$, temperature, time of the process, sampling, and analysis of the samples were performed in the same condition for all the experiments. Final ethanol concentration after 96 hours of SSF process is presented by $[E]_{\mathrm{f}}$ whereas the initial concentration of ethanol is stated by $[E]_{0}$ in Eq. 4.

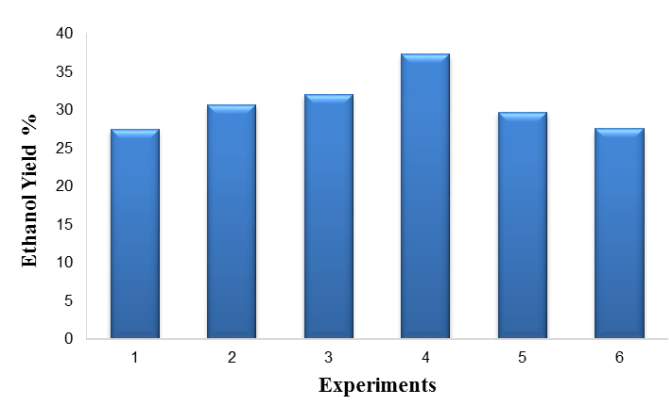

Fig. 1. Ethanol yield\% of the six SSF experiments. 
As seen from Fig. 1, Exp. 4 with the initial concentrations of $10 \mathrm{~g} / \mathrm{L}$ for glucose and $9 \mathrm{~g} / \mathrm{L}$ for mannose and enzyme loading of 15 FPU/g cellulose has the highest ethanol yield among all the experiments. The concentration profiles of glucose, mannose, cellobiose and ethanol are presented in Fig. 2 .
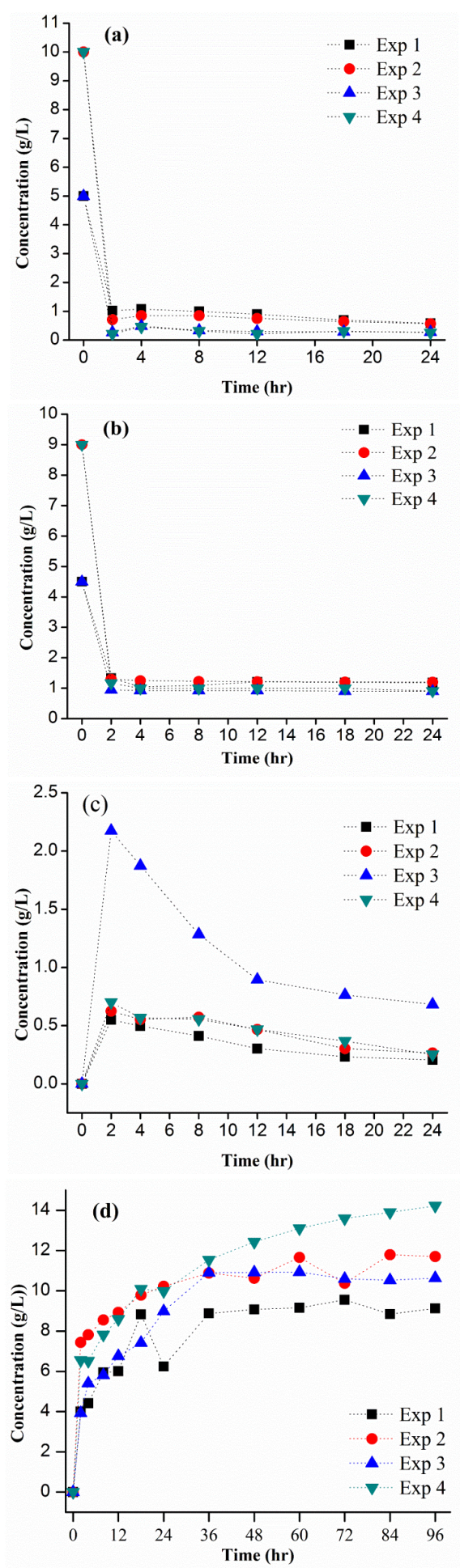

Fig. 2. Concentration profiles of (a) glucose (b) mannose (c) cellobiose and (d) ethanol for SSF experiments.

In each case, glucose and mannose present in the feed stock were quickly converted to ethanol, accompanied by dramatic changes in the concentrations of glucose, mannose and ethanol within the first 2 hours. After that, the concentrations of glucose and mannose varied very slightly. Concentration of cellobiose, an intermediate product converted from cellulose by means of cellulase enzyme, increased quickly to peak values in the first 2 hours and then declined gradually. In addition, increasing the cellulase loading helps to enhance the conversion of cellulose, which is disclosed by the higher cellobiose concentration obtained from Exps. $3 \& 4$ shown in Fig. 2(c).

\section{A. Impact of Initial Concentration of Fermentable Sugars}

Initial sugar concentration plays an important role in the SSF reaction. As seen from Fig. 2(d), increasing the glucose concentration from 5 to $10 \mathrm{~g} / \mathrm{L}$ and mannose from 4.5 to $9 \mathrm{~g} / \mathrm{L}$ led to the higher ethanol concentration and yield when low and intermediate levels of enzyme loadings were used. Nonetheless, at relative higher enzymatic loading (20 FPU/g cellulose), increasing the initial concentration of sugars resulted in a decrease in ethanol yield although a slightly higher concentration of ethanol was obtained in case of Exp. 6 (Fig. 3).

This is reasonable, with a fixed yeast concentration being used in the SSF process, higher concentration of fermentable sugars in the feedstock helps to produce more amount of ethanol, leading to higher ethanol concentration (reaction volume unchanged). But the increase in ethanol production is limited by the yeast loading and performance. As a result, the ethanol yield with respect to the total sugars in the media decreases at high initial concentration of sugars.

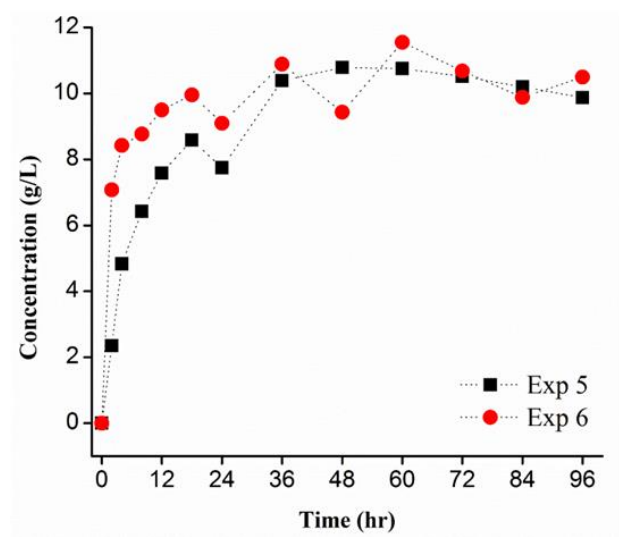

Fig. 3. Comparison of ethanol concentrations for Exps. 5 and 6 with enzyme loading of $20 \mathrm{FPU} / \mathrm{g}$ cellulose.

\section{B. Impact of Enzyme Loading}

Impacts of cellulase loading on ethanol yield and concentration were illustrated in Fig. 1 and Fig. 4, respectively. For each level of initial concentration of sugars, the highest ethanol yield and concentration were obtained with an enzyme loading of $15 \mathrm{FPU} / \mathrm{g}$ cellulose. In spite of the amount of soluble glucose and mannose present at the start of $\mathrm{SSF}$, increasing cellulase loading from $10 \mathrm{FPU} / \mathrm{g}$ cellulose to $15 \mathrm{FPU} / \mathrm{g}$ cellulose helps to improve both ethanol yield and ethanol concentration as illustrated in Fig. 1 \& Fig. 2(c). However, such an enhancement in ethanol production was not observed when further increasing the cellulase loading to 20 FPU/g cellulose due to the inhibitory effect of the cellobiose and glucose. High enzyme loading in the SSF process accelerates the rate of enzymatic hydrolysis, leading to higher concentrations of cellobiose and glucose, which according to 
Ishmayana et al. (2011) [25], exposes the yeast to high osmotic stress, influences on fermentation performance of the yeast and reduces the amount of produced ethanol. This means that for certain cellulose and yeast loading, there is an optimum enzyme loading, beyond which ethanol yield and concentration can't be increased.
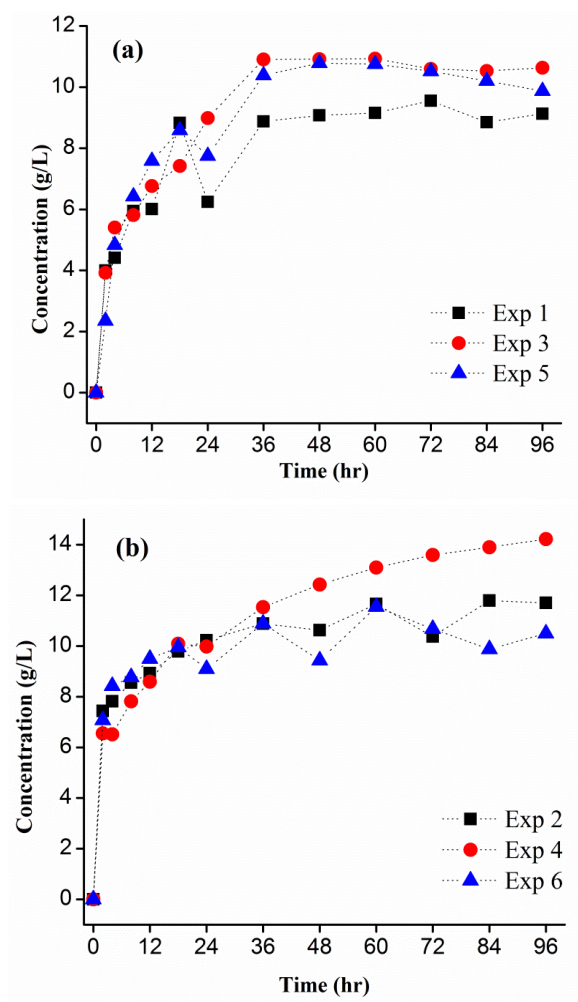

Fig. 4. Impact of enzyme loading on the ethanol concentration at different initial sugar concentrations (a) $5 \mathrm{~g} / \mathrm{L}$ glucose, and $4.5 \mathrm{~g} / \mathrm{L}$ mannose; and (b) $10 \mathrm{~g} / \mathrm{L}$ glucose, and $9 \mathrm{~g} / \mathrm{L}$ mannose.

\section{Interactive Impacts of Cellulase Loading and Initial Concentration of Sugars}

For SSF process with fixed substrate and yeast loading, the interplay between the enzyme loading and initial concentration of fermentable sugars is obvious. With lower initial concentration of sugars, the enhancement of ethanol yield and concentration is easily attainable by employing higher enzyme loading. However, due to the strong inhibitory effect of cellobiose and glucose, high enzyme loading results in a significant decrease in ethanol yield and concentration when the feedstock contains very high concentration of fermentable sugars. This provides useful information with respect to the optimization of SSF process. Depending on the substrate and sugar concentration in the feedstock of SSF, enzyme loading should be selected strategically.

\section{CONCLUSIONS}

Influences of enzyme loading and initial concentration of fermentable sugars on the final ethanol concentration and yield of SSF process was studied in this work. Results indicated that there is a saturation of enzyme loading for each level of sugar concentration. With 5\% (w/v) cellulose and $5 \mathrm{~g}$ dry cell/L yeast loading, ethanol concentration and yield can't be improved by purely increasing the enzyme loading.
Moreover, interactive impact of enzyme loading and initial concentration of fermentable sugars on SSF process was observed. High enzyme loading helped to increase the final ethanol concentration and yield if the initial concentration of fermentable sugars was low. However, high enzyme loading resulted in a decrease in ethanol concentration and yield when feedstock contains high concentration of fermentable sugars. Therefore, enzyme loading of SSF process need to be selected strategically from the process economics perspective.

\section{ACKNOWLEDGMENT}

Support of this research from NSERC Discovery Grant and Newfoundland Centre for Forest Science and Innovation are gratefully acknowledged. We would also like to thank Dr. Kelly Hawboldt for sharing with us her laboratory facilities.

\section{REFERENCES}

[1] Z. S. Zhu, M. J. Zhu, W. X. Xu, and L. Liang, "Production of bioethanol from sugarcane bagasse using $\mathrm{NH}_{4} \mathrm{OH}-\mathrm{H}_{2} \mathrm{O}_{2}$ pretreatment and simultaneous saccharification and co-fermentation," Biotechnology and Bioprocess Engineering, vol. 17, pp. 316-325, 2012.

[2] R. A. Jones, J. A. Gandier, J. Thibault, and F. H. Tezel, "Enhanced ethanol production through selective adsorption in bacterial fermentation," Biotechnology and Bioprocess Engineering, vol. 16, pp. 531-541, 2011.

[3] S. P. S. Chundawat, G. T. Beckham, M. E. Himmel, and B. E. Dale, "Deconstruction of lignocellulosic biomass to fuels and chemicals," Annu Rev Chem Biomol Eng, vol. 2, pp. 121-145, 2011.

[4] X. Q. Zhao, L. H. Zi, F. W. Bai, H. L. Lin, X. M. Hao G. J. Yue, and N. W. Y. Ho, "Bioethanol from Lignocellulosic Biomass," Adv Biochem Engin/Biotechnol, vol. 128, pp. 25-51, 2012.

[5] J. S. Van Dyk and B. I. Pletschke, "A review of lignocellulose bioconversion using enzymatic hydrolysis and synergistic cooperation between enzymes Factors affecting enzymes, conversion and synergy," Biotechnology Advances, vol. 30, no. 6, pp. 1458-1480, 2012.

[6] D. H. Cho, D, S. J. Shin, B. I. Sang, M. H. Eom, and Y. H. Kim, “ABE production from yellow poplar through alkaline pre-hydrolysis, enzymatic saccharification, and fermentation," Biotechnology and Bioprocess Engineering, vol. 18, pp. 965-971, 2013.

[7] G. P. Philippidis, T. K. Smith, and C. E. Wyman, "Study of the enzymatic hydrolysis of cellulose for production of fuel ethanol by the simultaneous saccharification and fermentation process," Biotechnology and Bioengineering, vol. 41, pp. 846-853, 1993.

[8] J. Rass-Hansen, H. Falsig, B. Jørgensen, and C. H. Christensen, "Prospective bioethanol: fuel or feedstock?" J Chem Technol Biotechnol, vol. 82, pp. 329-333, 2007.

[9] K. Hoyer, M. Galbe, and G. Zacchi, "Production of fuel ethanol from softwood by simultaneous saccharification and fermentation at high dry matter content," J ChemTechnol Biotechnol, vol. 84, pp. 570-577, 2009.

[10] Ó. J. Sanchez and C. A. Cardona, "Trends in biotechnological production of fuel ethanol from different feedstocks," Bioresour Technol, vol. 99, pp. 5270-5295, 2008.

[11] D. Klein-Marcuschamer, P. Oleskowicz-Popiel, B. A. Simmons, and H. W. Blanch, "The challenge of enzyme cost in the production of lignocellulosic biofuels," Biotechnology and Bioengineering, vol. 109, pp. 1083-1087, 2012.

[12] K. Brijwani, H. S. Oberoi, and P. V. Vadlani, "Production of a cellulolytic enzyme system in mixed-culture solid-state fermentation of soybean hulls supplemented with wheat bran," Process Biochem, vol. 45, pp. 120-128, 2010

[13] X. Fang, S. Yano, H. Inoue, and S. Sawayama, "Strain improvement of Acremonium cellulolyticus for cellulase production by mutation," $J$ Biosci Bioeng, vol. 107, pp. 256-261, 2009.

[14] M. P. Vasquez, J. N. C. Da Silva, M. B. De Souza, and N. Pereira, "Enzymatic hydrolysis optimization to ethanol production by simultaneous saccharification and fermentation," Applied Biochemistry and Biotechnology, vol. 136-140, pp. 141-154, 2007.

[15] J. C. Lopez-Linares, I. Romero, C. Cara, E. Ruiz, E. Castro, and M. Moya, "Experimental study on ethanol production from hydrothermal pretreated rapeseed straw by simultaneous saccharification and 
fermentation," J Chem Technol Biotechnol, vol. 89, pp. 104-110, 2014.

[16] K. Liu, X. Lin, J. Yue, X. Li, X. Fang, M. Zhu, J. Lin, Y. Qu, and L. Xiao, "High concentration ethanol production from corncob residues by fed-batch strategy," Bioresour Technol, vol. 101, pp. 4952-4958, 2010.

[17] K. Stenberg, M. Bollok, K. Reczey, M. Galbe, and G. Zacchi, "Effect of substrate and cellulase concentration on simultaneous saccharification and fermentation of steam-pretreated softwood for ethanol production," Biotechnology and Bioengineering, vol. 68, no. 2 , pp. 204-210, 2000.

[18] M. Balat, H. Balat, et al., "Progress in bioethanol processing," Prog Energy Combust, vol. 34, pp. 551-573, 2008.

[19] M. A. Neves, T. Kimura, N. Shimizu, and M. Nakajima, "State of the art and future trends of bioethanol production," Dynamic Biochemistry, Process Biotechnology and Molecular Biology, vol. 1, pp. 1-14, 2007.

[20] S. W. Cheung, and B. C. Anderson, "Laboratory investigation of ethanol production from municipal primary wastewater solids," Bioresource Technology, vol. 59, pp. 81-96, 1997.

[21] X. Huang and M. H. Penner, "Apparent substrate inhibition of the Trichoderma reesei cellulase system," J Agric Food Chem, vol. 39, pp. 2096-2100, 1991.

[22] P. Valjamae, G. Pettersson, and G. Johansson, "Mechanism of substrate inhibition in cellulose synergistic degradation," Eur J Biochem, vol. 268, pp. 4520-4526, 2001.

[23] Y. Sun and J. Cheng, "Hydrolysis of lignocellulosic materials for ethanol production: A review," Bioresource Technology, vol. 83, pp. $1-11,2002$.

[24] K. Hoyer, M. Galbe, and G. Zacchi, "Influence of fiber degradation and concentration of fermentable sugars on simultaneous saccharification and fermentation of high-solids spruce slurry to ethanol," Biotechnology for Biofuels, vol. 6, no. 1, pp. 145-153, 2013.

[25] S. Ishmayana, R. P. Learmonth, and U. J. Kennedy, "Fermentation performance of the yeast Saccharomyces cerevisiae in media with high sugar concentration," in Proc. the 2nd International Seminar on Chemistry, 2011, pp. 379-385.

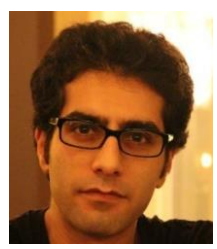

J. Shadbahr received his B.Sc and M.Sc in chemical engineering from Sharif University of Technology, Tehran, Iran in 2007 and 2009, respectively.

He was working as a process engineer in consulting engineering company as well as the oil refinery in tehran, iran and currently he is doing his phd in process engineering alongside research and teaching assistance at Memorial University of Newfoundland, St. John's, NL, Canada. He has publications in kinetic modeling of visbreaking reactions and life cycle assessment of bioethanol production and his current research interest include bioethanol production from lignocellulosic biomass.

Mr. Shadbahr is a member of Society of Petroleum Engineers (SPE) and also Graduate Students' Union (GSU) at Memorial University of Newfoundland.

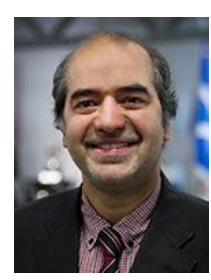

F. Khan is Professor and Director of Centre for Risk Integrity and Safety Engineering (C-RISE). He is also the Head of the Department of Process Engineering at Faculty of Engineering \& Applied Science, Memorial University, Canada. His areas of research interest include: offshore safety and risk engineering, asset integrity management, inherent safety, and risk-based integrity assessment and management. He is actively involved with multinational oil and gas industries on the issue of safety and asset integrity.

Dr. Khan's global engagement efforts lead to AMC signing memorandum of understanding with NTNU, Norway; ITS, Indonesia; UTM, Malaysia; and Tokyo University, Japan. He is recipient of President Outstanding Research Award of 2012-13, CSChE National Award on Process Safety Management of 2014, and President Outstanding Research Supervision Award of 2013-14. He has authored five books and over 270 research articles in peer reviewed journals and conferences on safety, risk and reliability engineering. He has authored five books on the subject area. He is an editor to Journal of Process Safety and Environmental Protection, Journal of Loss Prevention, and Journal of Process Engineering.

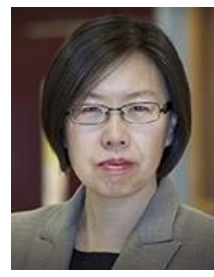

Y. Zhang graduated B. Eng. and M. Eng. in chemical engineering from Tianjin University, Tianjin, China and received her $\mathrm{PhD}$ degree in 2006 from the Department of chemical and biomolecular Engineering at National University of Singapore.

She worked as a postdoctoral fellow at University of Western Ontario from 2006 to 2010 and prior to that she was working as senior Process Engineer in China. She joined the Faculty of Engineering and Applied Science at Memorial University of Newfoundland as an assistant professo in 2010. Her current research interests include developing sustainable functional materials and biofuel from natural polysaccharides, process simulation and optimization. Dr. Zhang has authored more than 40 research articles in peer reviewed journals and conferences on fabrication of novel biosorbent, advanced separations of proteins and pharmaceutical intermediates as well as process simulation and optimization.

Dr. Zhang is a member of Chemical Institute of Canada, Association of Professional Engineers Ontario, and Association of Professional and Geoscientists of Newfoundland \& Labrador. 